\title{
DE KOLONIALE STATEN EN DE BELANGEN VAN DEN GROOTEN LANDBOUW IN DE LANDBOUWKOLONIE SURINAME
}

\author{
DOOR
}

MR. DR. C. F. SCHOCH

(Oud-lid der Koloniale Staten van Suriname)

$\mathrm{Er}$ is de laatste weken groote ontroering gewekt bij allen in Nederland, die belangen in de kolonie Suriname hebben te behartigen of zich uit zuivere belangstelling met die kolonie bezighouden. Daar is in Suriname iets gebeurd, waaraan men in onze gematigde luchtstreek niet anders dan met verbazing en ergernis denken kan en men vraagt zich af: wat helpen alle pogingen om de kolonie op te heffen uit den tragischen toestand, waarin zij zich bevindt, indien de wettelijke vertegenwoordiging van de Surinaamsche bevolking die pogingen tegenwerkt of met onbegrijpelijke lichtvaardigheid afbreekt, wat zij kort te voren mede hielp opbouwen. En men denkt met groote ongerustheid aan plannen en voorstellen om die volksvertegenwoordiging meer invloed op het bestuur der kolonie te geven en Suriname in de praktijk meer autonoom te maken, dan zij nu is.

Wat mij aanleiding geeft het bovenstaande neer te schrijven, is het gebeurde op 7 Januari jl., toen de Koloniale Staten met 7 stemmen tegen 4 stemmen verwierpen eene ontwerp-verordening genoemd: „Steunverleening 1924 aan cacao- en koffieondernemingen".

Tot recht begrip van de zaak dient de geschiedenis in het kort te worden aangegeven.

Reeds sedert jaren wordt in de landbouwkolonie Suriname de klacht geuit, dat de cultuur van stapelproducten op de ondernemingen te zwaar belast wordt. Voor 
den aanvoer van contractarbeiders moest jaren lang door de ondernemingen $3 / 5$ van de kosten worden betaald. Het overige werd uit eene Regeeringsinstelling, het Immigratiefonds, geput, dat door, van Regeeringswege uitgegeven, leeningen in Nederland zijn kapitaal verkreeg. Bovendien moeten de ondernemingen aan allerlei eischen ten aanzien van ruime en sanitaire arbeiderswoningen voldoen, een hospitaal onderhouden, bijdragen in de kosten van den geneeskundigen dienst, een zeker akkergeld betalen, benevens eene grondrente voor in den tijd der mislukte bacovencultuur door het Koloniaal Gouvernement betaalde kosten.

$\mathrm{Na}$ het verschijnen van het rapport van het Suriname Studie Syndicaat in 1920 werd in de plaats van de verplichte gedeeltelijke betaling van de aanvoerkosten eene regeling in het leven geroepen, bepalende, dat voor elken werkdag van een gecontracteerden immigrant door den werkgever 15 cent aan het Immigratiefonds moest worden vergoed.

Onder al die opgelegde lasten gaan de cacao- en koffieondernemingen de laatste jaren zwaar gebukt, omdat de toestand van die cultures allesbehalve schitterend is. Sedert het begin van deze eeuw moest voortdurend de strijd aangebonden worden tegen de den cacaoboom teisterende ziekten of insecten. Was de eene aanval schijnbaar overwonnen, dan kwam een ander de gemoederen weder verontrusten, zoodat menige cacaoplantage in de laatste 20 jaren is verlaten of wel omgezet in eene koffieonderneming. Daarbij kwam ten slotte de vrijwel onverkoopbaarheid van het product, doordat ergeen vraag opde wereldmarkt was en hoeveelheden cacao geruimen tijd te New York en te Amsterdam moesten worden bewaard. De koffiecultuur had niet geheel dezelfde lotgevallen, omdat in de oorlogsjaren mooie prijzen werden gemaakt en niet zoovele ziekten den koffieboom teisterden. Allerwege werd dan ook koffie aangeplant, de soort veredeld en de bereiding verbeterd. De daling in prijs in de laatste jaren maakte echter de exploitatie voor de ondernemingen jaarlijks tot een belangrijk verlies en zij kwamen steeds dieper in de schuld. 
Deze wanhopige toestand leidde eindelijk in 1923 de belanghebbenden bij die cultures in Nederland tot eene gezamenlijke actie. Uit den nood werd de eendracht geboren en men wendde zich tot de Regeering met het dringend en gedocumenteerd verzoek om verlichting van de lasten, die drukten op een bedrijf, waarop geregeld moest worden bijgepast.

De Minister van Koloniën gevoelde geen vrijheid om thans wijziging te brengen in de bestaande regelingen, maar verkreeg de overtuiging, dat er toch iets moest worden gedaan en vroeg daarom het oordeel van den Gouverneur over eene steunverleening in de crisis, die de landbouw doormaakte, door over de jaren 1923 en 1924 aan de cacao- en koffieplantages kwijtschelding te verleenen van de vergoeding van 15 cent per werkdag, die de ondernemingen voor immigranten hebben te betalen. De Minister verzocht daarbij tevens het gevoelen van de Koloniale Staten ter zake in te winnen.

De Gouverneur gaf hieraan uitvoering en op den 27en December 1923 verklaarden de Koloniale Staten met 9 van de 11 in de kolonie aanwezige en ter vergadering tegenwoordige leden zich voor dezen maatregel, mits het achterstallige over vorige jaren zou worden aangezuiverd. Van de twee tegenstemmende leden meende één zich in beginsel te moeten verzetten tegen kwijtschelding van de verschuldigde bijdrage, doch wel te zijn vóór een te verleenen uitstel van betaling, desnoods verdeeld over 10 jaren. Het andere lid stemde tegen, omdat de voorgestelde maatregel geen duurzame verbetering in den toestand der ondernemingen zou brengen. Doeltreffende hulp zou alleen geboden worden, indien bv. de betaling van de verschuldigde belastingen gedurende vijf jaren zou worden opgeschort.

De Gouverneur van Suriname, Baron van Heemstra, kon zich met deze meening van de Koloniale Staten geheel vereenigen en de Minister van Koloniën vond daarin vrijheid bij nota van wijzigingen in het wetsontwerp tot vaststelling van de Koloniale huishoudelijke begrooting van Suriname voor 1924 de noodige voorzieningen te tref- 


\section{DE BELANGEN VAN DEN GROOTEN LANDBOUW}

fen, die Zijne Excellentie aan de Tweede Kamer der Staten-Generaal toelichtte op eene zoo duidelijke wijze, dat die, naar mijne meening, voor de volledigheid hier dient weergegeven.

De Minister schreef den 27en Maart 1924 aldus:

„De sterke daling in de laatste jaren van de verkoopprijzen van „cacao en koffie, inzonderheid verband houdende met de door de „gevolgen van den wereldoorlog ongunstig beinvloede koop„kracht van groote groepen consumenten van die landbouw„voortbrengselen, heeft in steeds toenemende mate het in gang „houden bemoeilijkt van de, op enkele weinige uitzonderingen na, „niet-kapitaalkrachtige ondernemingen in Suriname, waarop „bedoelde producten worden geteeld”.

„Reeds is van een tiental ondernemingen van dien aard de ex„ploitatie gestaakt, terwijl, als de omstandigheden niet spoedig „veranderen, het bereids tot het uiterste ingekrompen bedrijf op „het meerendeel der overige koffie- en cacao-plantages niet lang „meer zal kunnen worden voortgezet.

„Het behoeft geen betoog, dat staking van die bedrijven nood„lottige gevolgen zou dragen, zoowel door deneconomischen toe„stand en voor den stand der geldmiddelen van de kolonie, als „voor de toekomst van het gewest.

„Teneinde aan de kolonie het behoud van de onderhavige „landbouwondernemingen te verzekeren, zag het Koloniaal Be„stuur zich voor de noodzakelijkheid geplaatst voorzieningen te „overwegen, die er toe zouden kunnen leiden, dat, in afwachting „van eene blijvende verbetering in de marktpositie van koffie en „cacao, ten aanzien waarvan bereids enkele, zij het wellicht nog „zwakke aanwijzingen zijn te bespeuren, in den last der geldelijke „bezwaren voor de betrokken ondernemingen eenige verlichting „komt.

„Tot de dienaangaande tusschen den Gouverneur en den on„dergeteekende gevoerde gedachtenwisseling heeft rechtstreeks „aanleiding gegeven een ten vorigen jare ingekomen verzoek van „een aantal belanghebbenden hier te lande bij Surinaamsche cul„tuurondernemingen. Bij dat verzoek werd aangedrongen op eene „herziening van de op de productiekosten bij het plantagebedrijf „in de kolonie van invloed zijnde landsheffingen en regelingen be„treffende immigratiekosten, in dien zin, dat de daardoor op de „kostprijzen van het product uitgeoefende druk zou worden ver"minderd, alsmede op de totstandbrenging, in afwachting van 
„zoodanige herziening, van tusschentijdsche maatregelen, die „reeds dadelijk ten aanzien van de door de tijdsomstandigheden ge„,boden noodzaak, om tot verlaging van de productiekosten van „,koffie en cacao te geraken, nuttig effect zouden sorteeren.

„In verband met den huidigen benarden toestand van 's Rijks „geldmiddelen heeft de ondergeteekende bij de evenbedoelde ge„dachtenwisseling op den voorgrond moeten stellen, dat wanneer „voorzieningen van dien aard gepaard zouden gaan met derving „van inkomsten van de Kolonie, slechts dan uitzicht zou bestaan „op medewerking van het Opperbestuur, indien elders op de be„grooting reëele compensatie voor zoodanige inkomstenderving „zou worden gevonden, m. a. w. als uit dien hoofde geene nieuwe „lasten op 's Rijks schatkist zouden worden gelegd.

„De Landvoogd heeft, in aansluiting hieraan, in overeenstem„ming met de Koloniale Staten zich er voor uitgesproken om, af„gezien van hetgeen te zijner tijd zal worden beslist ten aanzien „van eene principieele herziening van het voor deplantagebedrijven „in het algemeen geldend samenstel van landsheffingen enz. als „hiervóór bedoeld, voor het tegenwoordige de koffie- en cacao„ondernemingen tegemoet te komen langs den weg van eene tij„delijke staking der inning van één der ten bate van de geldmid„delen van het Immigratiefonds komende betalingen wegens de „tewerkstelling op die ondernemingen van door bemiddeling van „dat Fonds aangevoerde immigranten. Het ligt namelijk in de be„doeling, dat de betrokken werkgevers zullen worden vrijgesteld „van de betaling der ingevolge de koloniale verordening van 10 „December 1920 (Gouvernementsblad N ${ }^{\circ}$. 102) verschuldigde ver,goeding aan het Fonds over 1923 en 1924, ten bedrage van vijf„tien cent per werkdag, voor elken zoodanigen arbeider, met dien "verstande nochtans, dat zulks ten aanzien van achterstallige be„,talers van die vergoeding alleen dan zal geschieden, als het ver„schuldigde over voorafgaande betalingstijdperken alsnog binnen „bekwamen tijd aangezuiverd wordt.

„De heffingen, welke rechtstreeks ten bate komen van de Ko„loniale kas, worden op die wijze niet aangetast, terwijl mede ver"meden wordt eene executie van de plantages ter zake van be"doelde schuld, welke, zooals de Landvoogd bericht, onder de be„staande omstandigheden vrijwel gelijk zou staan met het doen „verdwijnen van die landbouwondernemingen als zoodanig.

„De uit de voorschreven voorziening voortvloeiende inkom„stenderving van het Immigratiefonds wordt becijferd op ,f 150.000.- over 1923; rekening houdende met de geldelijke ge- 
„volgen voor de inkomsten van het Fonds van de „hiervóór ver„melde verplichting tot aanzuivering van achterstallige betalin„gen door hen, die onder de onderhavige regeling vallen, zullen ,die inkomsten in 1924 slechts met $f$ 50.000.- terugloopen.

„Aan het navolgende dient nochtans aandacht te worden ge„geven. In afwachting van de uitgifte van eene nieuwe koloniale „geldleening ten behoeve van de immigratie, waardoor mede de „nadeelige bedrijfssaldi van het Immigratiefonds sedert de laat„ste leening tot vereffening zullen geraken, worden uit de kolo„niale kas jaarlijks bedrijfsvoorschotten aan het Fonds verstrekt, „met welke uitgaven op de begrooting rekening wordt gehouden „,(vgl. artikel 77 van de begrooting voor 1923 en artikel 78 van „het wetsontwerp). Door de hiervóór bedoelde inkomstenderving „van het Fonds zou uit de onderhavige voorziening ten behoeve „van de cacao- en koffieondernemingen zijdelings eene bezwaring „van de koloniale begrootingen voor 1923 en 1924 tot de voor„melde bedragen veroorzaakt worden, ware het niet dat in de „uitgaven van het Fonds van die jaren eene zoodanige beperking ,is en zal worden bereikt, dat verzwaring van den uit bedoelden „hoofde op de begrooting rustenden druk uitgesloten zal zijn.

„In dit verband komt het gewenscht voor om reeds thans, „voor zooveel namelijk de begrooting voor 1924 betreft, met de „uitkomsten van die beperking van uitgaven rekening te houden. „Daarom wordt bij de onderhavige Nota van Wijzigingen de ra„ming van het bij artikel 78 uitgetrokken krediet voor ,Voorschot"ten uit de Koloniale kas aan het Immigratiefonds" met $f 50.000$. „verminderd. Tevens worden bij deze Nota de wijzigingen voorge„steld, die in de als begrootingsstuk No. 4 gedrukte „Raming der „opbrengst van de middelen en inkomsten van de kolonie Suri„name voor het dienstjaar 1924" dienen te worden aangebracht.

„De overeenkomstige, elkander compenseerende wijzigingen, ,in de begrooting voor 1923 aan te brengen, zullen aan de orde „worden gesteld bij het in den loop van dit jaar in te dienen wets„ontwerp voor de regularisatie van die begrooting".

Op grond van de in December 1923 te dezer zake met de Koloniale Staten verkregen overeenstemming en de daarna, in verband daarmede, in de Koloniale begrooting door de Regeering gemaakte wijzigingen, welke de goedkeuring van de Staten-Generaal hadden verkregen, diende de waarnemende Gouverneur Mr. L. J. Rietberg, den 11 en Augustus 1924 bij de Koloniale Staten eene ont- 
werp-verordening in, om de tijdelijke vrijstelling in legalen vorm te doen vastleggen.

In het eindverslag, daarop door de Koloniale Staten den 15 en November 1924 uitgebracht, verwees men naar de te dezer zake gevoerde beraadslagingen en verklaarde op hetzelfde standpunt te blijven staan, als destijds aangegeven. Dus 9 van de 11 leden van de Koloniale Staten waren en bleven voor de voorgestelde kwijtschelding.

Toen de ontwerp-verordening den 7en Januari jl. in openbare vergadering door de Koloniale Staten werd behandeld, dus nog geen twee maanden, nadat zij een gunstig eindverslag hadden uitgebracht, werd de voordracht - mirabile dictu - met 7 stemmen tegen en 4 stemmen voor verworpen. Vijf van de 11 Statenleden waren dus in zeven weken tijds absoluut van meening veranderd.

De motieven, welke voor die frontverandering werden aangevoerd, waren eensdeels, dat het voorstel niet ver genoeg ging en slechts een lapmiddel was, zooals men zeide, waarmede de noodlijdende plantages niet geholpen waren, terwijl afdoende hulp aan de plantages noodzakelijk was, anderdeels, dat de koffieprijs momenteel hoog was, en de plantages steun dus niet meer noodig hebben, omdat zij thans weder geld verdienen.

Beide motiveeringen getuigen helaas van de verregaande kortzichtigheid en het gebrek aan kennis bij de aldus tegenstemmende leden der Koloniale Staten, ten opzichte van de zaak, waarover zij geroepen waren te oordeelen.

Wat het niet afdoende zijn der voorgestelde regeling betreft, de heeren hadden, na hetgeen ten deze reeds was voorgevallen, in afwachting van eene betere en definitieve regeling ten minste reeds kunnen aanvaarden, wat door het Koloniaal Bestuur, na overleg met de Nederlandsche Regeering werd aangeboden. En ten aanzien van den hoogen koffieprijs konden de heeren weten, dat door het gebrek aan oogst - door de groote droogte van einde 1923 en begin 1924 zou een groot deel van den oogst 1924 toch eerst in 1925 geplukt worden - het in eenige mate voordeel hebben van den hoogen koffieprijs uitgesloten was en dat zelfs één of twee jaren van hooge prij- 
zen voor de meeste plantages nog niet veel anders zou beteekenen dan een zich herstellen van den ernstigen toestand, waarin de ondernemingen zijn geraakt ten gevolge van de zeer lage prijzen, welke de laatste jaren gegolden hebben.

Het is hoogst betreurenswaardig te achten voor de kolonie, dat het vertegenwoordigend college thans eene afwijzende houding heeft aangenomen tegenover de door Regeering en Koloniaal Bestuur aan de kolonie geboden steun. De leden van de Koloniale Staten, al zijn dan slechts enkelen van nabij met den zoogenaamd grooten landbouw, de teelt van stapelprodukten, bekend, kunnen en moeten toch allen weten hoe zwaar de landbouwondernemingen in de laatste jaren gebukt zijn gegaan onder den druk der omstandigheden en hoe het een eerste eisch is voor eene wederopleving van onze zuivere landbouwkolonie, dat de cultures weder profijt gaan opleveren. En ook kunnen en moeten zij weten, dat er nog jaren voorbij zullen gaan, voordat er weder van bloeiende cultuurondernemingen zal kunnen sprake zijn, terwijl op bloei niet te rekenen valt, tenzij de lasten verlicht worden.

$\mathrm{Nu}$ was de voorgestelde maatregel natuurlijk slechts een tijdelijk hulpmiddel, maar daarmede werd een eerste stap gezet op een weg, die leiden moet tot grondige herziening van het geheele stelsel van lasten, afkomstig uit een tijd, toen eene vreemde mogendheid hare eischen stelde ten aanzien van de behandeling en verzorging van hare Britsch-Indische onderdanen en die eischen kracht bijzette door den stok achter de deur.

De aan de ondernemingen opgelegde verplichting om een deel der aanvoerkosten van de immigranten te betalen is, naar mijne meening geheel uit den tijd. De kolonie moet die kosten dragen, want zij voert niet meer voor een korten tijd ( 5 jaar) gecontracteerde arbeïders aan, maar aanstaande kolonisten. Zoolang het Koloniaal Bestuur zich niet zoo zeer op kolonisatie van de BritschIndiërs en Javanen toelegde, kon het standpunt verdedigd worden, dat de immigratie grootendeels ten voordeele van de cultuurondernemingen geschiedde. Dit is echter onjuist sedert het Koloniaal Bestuur vestigings- 
plaatsen op allerlei punten van de kolonie heeft doen aanleggen en daarmede als 't ware de immigranten uitnoodigt om na afloop van hun dienstverband zich als vrije kolonisten te vestigen, hun daarbij nog vrijdom van allerlei lasten gevende en $f$ 100.- premie, als zij afstand doen van het recht op terugvoer. De ondernemingen krijgen nu de immigranten, leeren hun den landbouw, die voor Suriname geëigend is, worstelen met hen de acclimatisatieperiode door en staan hen, na een paar jaar, aan de koloniale maatschappij af, als in de kolonie ingeburgerde, voor kolonist geschikte menschen, die hun deel zullen betalen aan de opbrengst der koloniale middelen, en door hun arbeid mede zullen werken om de kolonie tot den zoo gewenschten bloei te doen komen.

De ondernemingen hebben een paar jaar het voordeel van de immigratie, de kolonie zelve heeft er vele jaren lang het profijt van.

Het telkens door mij van kapitaalkrachtige in Nederlandsch-Indië werkende maatschappijen en personen vernomen bezwaar tegen het vestigen in Suriname van eene onderneming is, dat men door de opvattingen van de Koloniale Staten in de kolonie geen bedrijfszekerheid heeft.

De beslissing van 7 Januari 1925 heeft die meening weder krachtig voedsel gegeven en juist, nu van verschillenden kant, in verband met het verblijf van Gouverneur van Heemstra in Nederland, ernstig aan proefnemingen in de kolonie gedacht wordt, het crediet van de kolonie een stevigen stoot omlaag gegeven en de vraag opnieuw doen rijzen, wat men heeft aan een vertegenwoordigend lichaam, dat zulke besluiten neemt.

Het is te hopen, dat de Gouverneur, gesteund door den Minister van Koloniën, een middel zal weten te vinden om de in uitzicht gestelde vrijstelling toch werkelijkheid te doen worden.

In het Maartnummer van de West-Indische Gids heeft de Heer D. Coutinho in zijne studie, getiteld „Schorsing van Koloniale Verordeningen" op dezelfde gevaren gewezen, waar hij een schorsingsrecht van de Kroon zonder termijnbepaling bedenkelijk achtte om de daardoor 
geschapen onzekerheid in de wetgeving. Terecht schreef hij: ,iedere zakenman wenscht zekerheid, niemand zal kapitaal steken in een land, waar één ondoordachte Regeeringsdaad, zelfs na langen tijd, hem onherstelbare schade zal kunnen berokkenen". En aan het slot van zijn artikel laat de Heer Coutinho, op wiens oordeel ik altijd prijs heb gesteld, zich aldus uit: „,maar wat een goed en wijs Bestuur wèl vermag, is alle hinderpalen uit den weg ruimen welke den opzet en den voortgang van ondernemingen kunnen verhinderen of belemmeren, en zoodanige wettelijke regelingen te maken, waardoor het kapitaal, dat zijn weg naar dit land zoekt, worde aangemoedigd en vooral niet afgeschrikt."

Dat onderschrijf ik volkomen. De Heer Coutinho zag in zijn geval, door zijn onderwerp, uitsluitend naar de Nederlandsche Regeering. Ik pas hetzelfde toe, om dezelfde redenen, op het college der Koloniale Staten. Caveant consules, dat ook de buitenlanders omtrent de macht, die in de kolonie de wetgevende bevoegdheid uitoefent eenstemmig gunstig oordeelen.

Waar ik mijn levensarbeid geef aan pogingen om den bloei van de kolonie te bevorderen, acht ik mij gerechtigd vrijuit mijne meening ten deze te uiten.

Amsterdam, 10 Maart 1925. 